systems tends to be given short shrift. As a result, "productive cross-fertilization between model systems and human biology" is lost, removing an important link between basic science and human medicine. The past century of research on various nonmammalian model systems makes this point vividly. For example, studies of the nematode Caenorhabditis elegans have provided a wealth of information on cellular differentiation, neural networks, meiosis and programmed cell death; and studies of the fruit fly Drosophila melanogaster have substantially advanced our understanding of the mechanisms that underlie Mendelian genetics.

Decisions about government funding of research are important for several reasons.
The amount of money involved is large (the budget of the NIH alone is just over \$29 billion), there is intense competition for grants (only about 19\% of proposals to NIH are currently funded), and government-supported basic research is capable of providing the substrate for many future medical advances.

The history of high-quality basic research is a reminder that what we see in Kirschner's rear-view mirror can be important in moving society forward.

COMPETING FINANCIAL INTERESTS

The author declares no competing financial interests.

\section{Henry I Miller}

Henry I. Miller is at the Hoover Institution,

Stanford University, Stanford, California, USA.

e-mail:henry.miller@stanford.edu

\title{
GM food in the public mind-facts are not what they used to be
}

\begin{abstract}
To the Editor: concerning public reluctance about genetically modified (GM) crop cultivation and GM food. It also makes plain, however, that there still is quite a bit of confusion about the nature of the problem-a confusion that continuously obstructs the path toward a sustainable solution.

Calls for the public to appreciate the 'facts of the matter' refer to an evergreen concept that, I'm sure, makes
\end{abstract}

Your September editorial ${ }^{1}$ makes a brave attempt to make sense of the 'puzzle' for much back-patting in scientific communities. Another partystarter used to be the notion of those pesky 'irrational' consumers. It is a relief to see that the endless discussions about trust and confidence in social science have finally made it to the scientific nexus: no, people don't read scientific reports, they listen to somebody they trust. But yes, it is a huge problem in this debate, as well as others, that the media tend to look for conflict rather than scientific consensus in some misunderstood pursuit of 'journalistic objectivity'. Naomi Oreskes and
Erik Conway's book The Merchants of Doubt ought to have been a chilling wake-up call to journalism as such ${ }^{2}$.

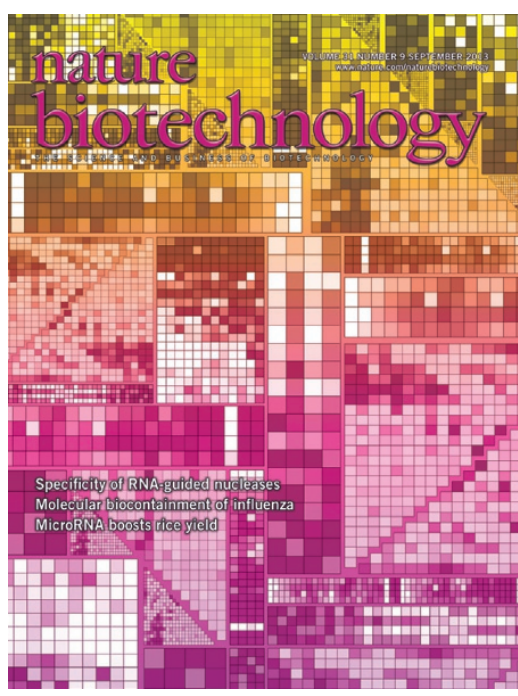

But that doesn't change the fact that agrichemical companies must ask themselves, with more persistence, why they are not (always) perceived as credible by the public. As the editorial hints, it very likely has to do with perceived alliances between regulators and industry-and, increasingly, scientists; in other words, as science increasingly becomes intertwined with various agendas, it looses credibilitythe facts are not what they used to be. No doubt the countless food scandals linked to industrial food production have also made an impression, not to mention the guarantees from experts that those scares are inconsequential. This track record has likely heightened public skepticism about GM foods, a response that appears quite understandable. The title of the Feature ${ }^{3}$ that accompanies the editorial- "How safe do transgenic crops need to be?" 3 -is, hence, at best misleading: for the public, safety in the scientific sense is but one aspect of the matter.

The question of why consumers are concerned about GM food is many-facetedfor 'consumers' or 'the public,' for example, are heterogeneous entities in terms of knowledge, attitude and engagement. But one may have to be a food scientist-thrilled by the opportunities-to find it mysterious why many consumers are fundamentally critical about any new food technology. To be sure, consumer benefits such as low price or added health benefit will persuade some people to buy GM food. Others will be convinced if the technology contributes to a solution for major societal problems such as global warming, as a UK study on synthetic biology has demonstrated ${ }^{4}$. But to really move the debate forward in a constructive way, we must ask: how can the entire agrifood system be incentivized so that its products merit the kind of public credibility it desires?

\section{COMPETING FINANCIAL INTERESTS}

The author declares no competing financial interests.

\section{Morten Andreasen}

Morten Andreasen works at The Danish Council of Ethics, Vanlose, Denmark.

e-mail:moa@dketik.dk

1. Anonymous. Nat. Biotechnol. 31, 767 (2013).

2. Oreskes, O. \& Conway, E. The Merchants of Doubt: How a Handful of Scientists Obscured the Truth on Issues from Tobacco Smoke to Global Warming (Bloomsbury, New York, 2010).

3. DeFrancesco, L. Nat. Biotechnol. 31, 794-802 (2013)

4. The Royal Academy of Engineering. Synthetic Biology: Public Dialogue on Synthetic Biology http://www.raeng.org.uk/news/publications/list/ reports/syn_bio_dialogue_report.pdf (The Royal Academy of Engineering, June 2009).

\section{The necessity of GM food for India}

\section{To the Editor:}

Your September Editorial ${ }^{1}$ argues that for genetically modified (GM) products to gain wider acceptability, they should address unmet needs. Although I fully agree with your closing statement, "In the end, necessity may turn out to be the mother of acceptance," I would like to point out that in a developing country like India, necessity goes beyond GM papaya to fight ringspot virus or GM orange to overcome citrus greening disease: for many in the population, 